\title{
The efficacy of N-Acetylcysteine in severe COVID-19 patients: A structured summary of a study protocol for a randomised controlled trial
}

Arash Rahimi ${ }^{1}$, Hamid Reza Samimagham ${ }^{1}$, Mehdi Hassani Azad ${ }^{2}$, Dariush Hooshyar ${ }^{3}$, Mohsen Arabi ${ }^{4}$ and Mitra KazemiJahromi ${ }^{5^{*}}$

\begin{abstract}
Objectives: Severe acute respiratory infection (SARI) caused by the SARS-CoV-2 virus may cause lung failure and the need for mechanical ventilation. Infection with SARS-COV-2 can lead to activation of inflammatory factors, increased reactive oxygen species, and cell damage. In addition to mucolytic effects, N-Acetylcysteine has antioxidant effects that we believe can help patients recover. In this study, we evaluate the efficacy of NAcetylcysteine in patients with severe COVID-19.
\end{abstract}

Trial design: This is a prospective, randomized, single-blinded, phase 3 controlled clinical trial with two arms (ratio 1:1) parallel-group design of 40 patients, using the placebo in the control group.

Participants: All severe COVID-19 patients with at least one of the following five conditions: (respiration rate $>30$ per minute), hypoxemia (O2 $\leq$ saturation, arterial oxygen partial pressure ratio <300), pulmonary infiltration (> 50\% of lung area during $2448 \mathrm{~h}$ ), Lactate dehydrogenase (LDH) $>245 \mathrm{U} / \mathrm{l}$, Progressive lymphopenia, and admitted to the intensive care unit of Shahid Mohammadi Hospital in Bandar Abbas and have positive PCR test results for SARSCov-2 and sign the written consent of the study will be included. Patients will be excluded from the study if they have a history of hypersensitivity to N-Acetylcysteine, pregnancy, or refuse to participate in the study.

Intervention and comparator: After randomization, participants in the intervention group receive standard of care (SOC) according to the National Committee of COVID-19 plus N-acetylcysteine (EXI-NACE 200 mg/mL, in 10mL ampules of saline for parenteral injection (EXIR pharmaceutical company)) at a dose of $300 \mathrm{mg} / \mathrm{kg}$ equivalent to 20 $\mathrm{gr}$ as a slow single intravenous injection on the first day of hospitalization. In the control group patients receive SOC and placebo ( Sterile water for injection as the same dose). The placebo is identical in appearance to the Nacetylcysteine injection (EXIR pharmaceutical company as well).

(Continued on next page)

\footnotetext{
* Correspondence: mitra.kazemijahromi@gmail.com

${ }^{5}$ Endocrinology and Metabolism Research Center, Hormozgan University of Medical Sciences, Bandar Abbas, Iran

Full list of author information is available at the end of the article
}

(c) The Author(s). 2021 Open Access This article is licensed under a Creative Commons Attribution 4.0 International License, which permits use, sharing, adaptation, distribution and reproduction in any medium or format, as long as you give appropriate credit to the original author(s) and the source, provide a link to the Creative Commons licence, and indicate if changes were made. The images or other third party material in this article are included in the article's Creative Commons licence, unless indicated otherwise in a credit line to the material. If material is not included in the article's Creative Commons licence and your intended use is not permitted by statutory regulation or exceeds the permitted use, you will need to obtain permission directly from the copyright holder. To view a copy of this licence, visit http://creativecommons.org/licenses/by/4.0/ The Creative Commons Public Domain Dedication waiver (http://creativecommons.org/publicdomain/zero/1.0/) applies to the data made available in this article, unless otherwise stated in a credit line to the data. 
(Continued from previous page)

Main outcomes: The primary endpoint for this study is a composite endpoint for the length of hospitalization in the intensive care unit and the patient's clinical condition. These outcomes were measured at the baseline (before the intervention) and on the 14th day after the intervention or on the discharge day.

Randomisation: Eligible participants (40) will be randomized in two arms in the ratio of 1: 1 (20 per arm) using online web-based tools and by permuted block randomization method. To ensure randomization concealment, random sequence codes are assigned to patients by the treatment team at the time of admission without knowing that each code is in the intervention or comparator group.

Blinding (masking): All participants will be informed about participating in the study and the possible side effects of medication and placebo. Patients participating in the study will not be aware of the assignment to the intervention or control group. The principal investigator, health care personnel, data collectors, and those evaluating the outcome are aware of patient grouping.

Numbers to be randomised (sample size): A total of 40 patients participate in this study, which are randomly divided; 20 patients in the intervention group will receive SOC and N-acetylcysteine, 20 patients in the control group will receive SOC and placebo.

Trial status: First version of the protocol was approved by the Deputy of Research and Technology and the ethics committee of Hormozgan University of Medical Sciences on February 14, 2021, with the local code 990573, and the recruitment started on March 2, 2021 and the expected recruitment end date is April 1, 2021.

Trial registration: The protocol was registered before starting participant recruitment entitled: Evaluation of the efficacy of $\mathrm{N}$-Acetylcysteine in severe COVID-19 patients: a randomized controlled phase III clinical trial, IRCT20200509047364N3, at Iranian Registry of clinical trials on 20 February 2021.

Full protocol: The full protocol is attached as an additional file, accessible from the Trials website (Additional file 1). In the interest in expediting dissemination of this material, the familiar formatting has been eliminated; this Letter serves as a summary of the key elements of the full protocol.

The study protocol has been reported in accordance with the Standard Protocol Items: Recommendations for Clinical Interventional Trials (SPIRIT) guidelines (Additional file 2).

Keywords: COVID-19, Randomised controlled trial, Protocol, N-acetylcysteine

\section{Supplementary Information}

The online version contains supplementary material available at https://doi. org/10.1186/s13063-021-05242-4.

Additional file 1. Full Study Protocol.

Additional file 2. SPIRIT 2013 Checklist: Recommended items to address in a clinical trial protocol and related documents.

\section{Acknowledgements}

This work was a dissertation supported by the Clinical Research Development Center of Shahid Mohammadi Hospital. Bandar Abbas. Iran. We are sincerely thankful to Miss Tayyebeh Zaree in the Clinical Research Development Center of Shahid Mohammadi Hospital.

\section{Authors' contributions}

M KJ. and A R. designed the study. All the authors contributed in data collection and manuscript writing. M KJ supervised the study. The author(s) read and approved the final manuscript.

\section{Funding}

This study is supported by the Deputy of Research and Technology of Hormozgan University of Medical Sciences; Also, this sponsor has no role in designing the study, collection, storage, and analysis of information and in preparing the manuscript.
Availability of data and materials

The authors have not still decided on the sharing of data.

\section{Declarations}

\section{Ethics approval and consent to participate}

The protocol was approved by the ethics committee of Hormozgan University of Medical Sciences on February 14, 2021, with the code IR.HUMS.REC.1399.539. (https://ethics.research.ac.ir/EthicsProposalView. php?id=180568)

The authors confirm that this trial has received ethical approval from the appropriate ethical committee as described above. Written prospective informed consent will be obtained from participants before involvement in the trial in the Persian language.

\section{Consent for publication}

Written informed consent will be obtained from all participants/subject's legally acceptable representatives before inclusion in the trial for collecting data, analysis, storage, and publishing it.

\section{Competing interests}

The authors declare that they have no competing interests.

\section{Author details}

${ }^{1}$ Clinical Research Development Center, Shahid Mohammadi Hospital, Hormozgan University of Medical Sciences, Bandar Abbas, Iran. ${ }^{2}$ Infectious and Tropical Diseases Research Center, Hormozgan Health Institute, Hormozgan University of Medical Sciences, Bandar Abbas, Iran. ${ }^{3}$ Student 
Research Committee, Faculty of Medicine, Hormozgan University of Medical Sciences, Bandar Abbas, Iran. ${ }^{4}$ Department of Internal Medicine and Public Health Research Center, Family Medicine Department, Iran University of Medical Sciences, Tehran, Iran. ${ }^{5}$ Endocrinology and Metabolism Research Center, Hormozgan University of Medical Sciences, Bandar Abbas, Iran.

Received: 29 March 2021 Accepted: 31 March 2021

Published online: 12 April 2021

\section{Publisher's Note}

Springer Nature remains neutral with regard to jurisdictional claims in published maps and institutional affiliations.

Ready to submit your research? Choose BMC and benefit from:

- fast, convenient online submission

- thorough peer review by experienced researchers in your field

- rapid publication on acceptance

- support for research data, including large and complex data types

- gold Open Access which fosters wider collaboration and increased citations

- maximum visibility for your research: over $100 \mathrm{M}$ website views per year

At $\mathrm{BMC}$, research is always in progress.

Learn more biomedcentral.com/submissions 